\title{
Comparison of Serum Apolipoprotein Levels of Diabetic Children and Healthy Children with or without Diabetic Parents
}

\author{
Mohammad Hashemi, ${ }^{1}$ Mohammad Saadat, ${ }^{1}$ Mohaddeseh Behjati, ${ }^{1}$ and Roya Kelishadi ${ }^{2}$ \\ ${ }^{1}$ Cardiology Department, Faculty of Medicine, Isfahan University of Medical Sciences, Isfahan, Iran \\ ${ }^{2}$ Pediatrics Department, Faculty of Medicine and Child Growth \& Development Research Center, \\ Isfahan University of Medical Sciences, Isfahan, Iran \\ Correspondence should be addressed to Mohaddeseh Behjati, behjati@med.mui.ac.ir
}

Received 4 April 2012; Accepted 10 May 2012

Academic Editor: Khosrow Adeli

Copyright (C) 2012 Mohammad Hashemi et al. This is an open access article distributed under the Creative Commons Attribution License, which permits unrestricted use, distribution, and reproduction in any medium, provided the original work is properly cited.

Introduction. The association of diabetes and atherosclerosis with disorders of lipids and lipoproteins, notably high apolipoprotein $\mathrm{B}(\mathrm{apoB})$ and low apolipoprotein A1 (apoA1) is well established. Because of the beginning of the atherosclerosis' process from early life, in this study, the plasma levels of apoAl and apoB were compared in diabetic children with type I diabetes mellitus(DM), healthy children with diabetic parents (HDPs), and healthy children with nondiabetic parents (HNDPs). Methods. This case-control study was conducted among 90 children aged 9-18 years. Serum levels of apoA and apoB were compared among 30 diabetic children (DM), 30 healthy children with diabetic parents (HDPs), and 30 healthy children with nondiabetic parents (HNDP). Results. The mean serum apoAl was higher in DM $(153 \pm 69 \mathrm{mg} / \mathrm{dL})$ followed by HNDPs $(138 \pm 58 \mathrm{mg} / \mathrm{dL})$ and HDPs $(128 \pm$ $56 \mathrm{mg} / \mathrm{dl}$ ), but the difference was not statistically significant. The mean apoB value in HNDPs was significantly lower than DM and HDPs $(90 \pm 21 \mathrm{mg} / \mathrm{dL}$ versus $127 \pm 47$ and $128 \pm 38 \mathrm{mg} / \mathrm{dL}, P<0.05$, respectively). The mean apoB levels in DM ( $127 \pm 47 \mathrm{mg} / \mathrm{dl})$ and HDP $(128 \pm 38 \mathrm{mg} / \mathrm{dL})$ were not statistically significantly different $(P>0.05)$. Conclusions. Diabetic children and healthy children with diabetic parent(s) are at higher risk of dyslipidemia and atherosclerosis. Thus for primordial and primary prevention of atherosclerosis, we suggest screening these children for low plasma apoA1 and high plasma apoB levels.

\section{Introduction}

Atherosclerosis is the most common cause of death in world [1]. Fatty streaks are the first atherosclerotic lesions and are developed since childhood. These lesions are also seen in a child of hyperlipidemic mothers. One of the risk factors of atherosclerotic cardiovascular disease is diabetes mellitus (DM) and is associated with worse prognosis in patients with diagnosed coronary artery disease. The risk of myocardial infarction (MI) in nondiabetic patients with and without previous history of MI is similar to diabetic patients without previous history of MI [2]. Then, treatment of risk factors in diabetic patients without previous history of MI should be the same with nondiabetic patients with previous history of MI [2].

The most important cause of atherosclerosis in diabetic patient's is diabetic dyslipidemia [2]. Diabetic dyslipidemia includes hypertriglyceridemia, increased LDL, decreased
HDL, high apoB and low apoAl [3]. High apoB, and low apoA1 levels seen in type II DM are associated with increased risk of atherosclerotic cardiovascular diseases [3]. Increased plasma glycosylated lipoproteins are also seen in diabetic patients [4]. Diabetic dyslipidemia is associated with quantitative and qualitative changes in plasma lipids and lipoproteins [3]. In type I DM mild changes in shape and content of atherogenic apoB occur that predispose patients to increased risk of atherosclerosis [5]. In these patients, classic lipid profile may be normal but patient is at increased risk of atherosclerosis [5]. Measurement of apoA1 and apoB in diabetic patients may be helpful in diabetic patients at risk of cardiovascular diseases. Benefits of measurement of apoA1 and apoB in diabetic children or healthy children with diabetic parents are not determined. These patients are at increased risk of cardiovascular diseases. So, In this study, plasma levels of apoA1 and apoB were compared in diabetic children with type I diabetes mellitus (DM), healthy children 


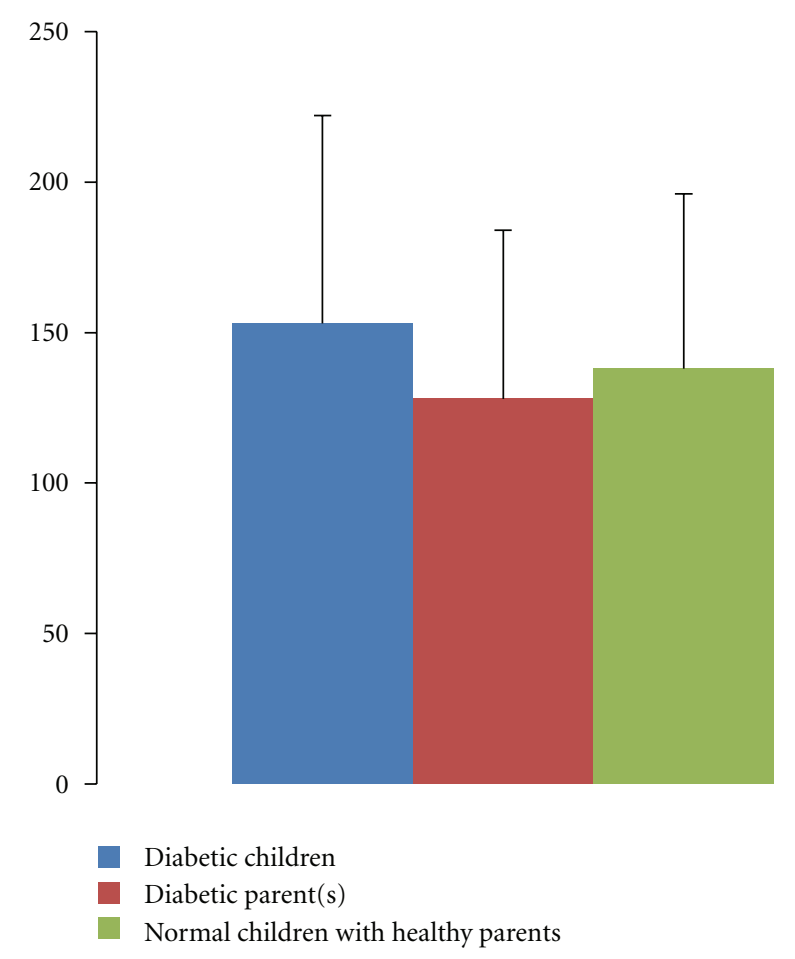

Figure 1: Comparison between serum apoA1 level in diabetic children, normal children with healthy parent(s), and healthy children with nondiabetic parents.

with nondiabetic parents (HNDPs), and healthy children with diabetic parents (HDPs).

\section{Methods and Materials}

In this case-control study, three groups of children (918 years old) were selected by simple random sampling: 30 healthy children (FBS $<110 \mathrm{mg} / \mathrm{dL}$ ) without diabetic parents (HNDPs), 30 healthy children with diabetic parents (one or both) (HDPs), and 30 children with diagnosis of diabetes (DM) and under the treatment with Insulin for at least 2 year, both males and females. Exclusion criteria were poor control diabetes with $\mathrm{HbAlC}>8.5 \%$, history of lipodystrophy, glycogen storage disease, chronic kidney disease, nephritic syndrome, glomerulonephritis, chronic liver disease, physical inactivity, obesity, high-fat diet, alcohol consumption, hypothyroidism, treatment with corticosteroid, retinoid drugs, immune suppressive drugs, growth hormone, hydrochlorothiazide, beta-blockers, and steroid hormones. Serum levels of apoA (reference limit: 94$199 \mathrm{mg} / \mathrm{dL}$ ) and apoB (reference limit: $60-133 \mathrm{mg} / \mathrm{dL}$ ) were measured by Kits with $95 \%$ sensitivity (Parsazmon, Iran) using immunoturbidimetery method.

\section{Results}

The mean value of apoA1 in DM was $138 \pm 58 \mathrm{mg} / \mathrm{dL}$ lower than healthy children with mean values of $153 \pm$ $69 \mathrm{mg} / \mathrm{dL}$, but this difference was not statistically significant

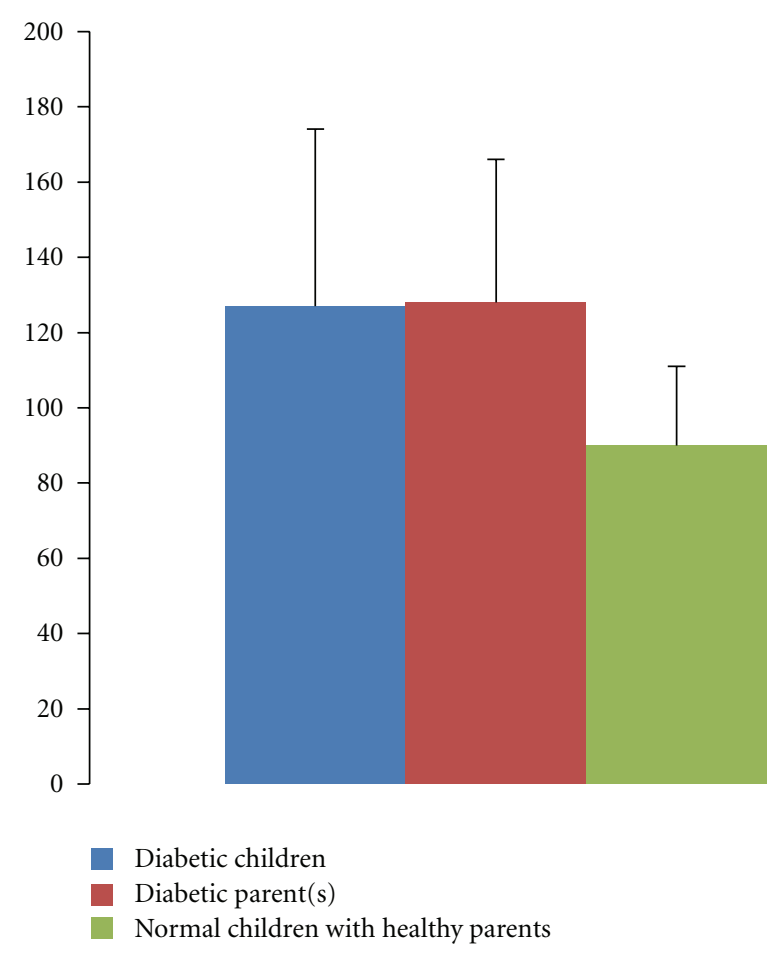

Figure 2: Comparison between serum apoB level in diabetic children, normal children with healthy parent(s), and healthy children with nondiabetic parents.

$(P>0.05)$. The mean value of apoAl in healthy children with nondiabetic parent(s) $128 \pm 56 \mathrm{mg} / \mathrm{dL}$ was higher than healthy children with diabetic parent(s), but this difference was not statistically significant $(P<0.05)$. The mean value of apoA1 in diabetic children was higher than healthy children with diabetic parent(s), but this difference was not statistically significant $(P>0.05)$ (Table 1$)$. Mean apoB value in healthy children with nondiabetic parent(s) was $90 \pm 21 \mathrm{mg} / \mathrm{dL}$ which was significantly lower than diabetic children with mean values of $127 \pm 47 \mathrm{mg} / \mathrm{dL}(P<0.05)$. The mean apoB levels in healthy children with nondiabetic parent(s) were $90 \pm 21 \mathrm{mg} / \mathrm{dL}$ which was significantly lower than children with diabetic parent(s) with the mean level of $128 \pm 38 \mathrm{mg} / \mathrm{dL}$, but this difference was not statistically significant $(P>0.05)$ (Table 2$)$. The Mean levels values of apoA1 and apoB in healthy children with nondiabetic parents, healthy children with diabetic parents, and diabetic children are shown in Figures 1 and 2, respectively.

\section{Discussion}

The most common cause of death in diabetic is atherosclerotic cardiovascular disease [2]. Multiple cardiovascular risk factors like hypertension, obesity, and cigarette smoking are common in both type I and II DM, but diabetic dyslipidemia is the most important cause of increased risk of atherosclerosis in diabetic patients [2]. Increase of apoB in diabetic patients demonstrates increased plasma atherogenic lipids [3]. Decreased HLD is also associated 
TABLE 1: Comparison of apoA1 levels in diabetic children, healthy children with diabetic parent(s), and healthy children with nondiabetic parent(s).

\begin{tabular}{|c|c|c|c|c|}
\hline \multirow[b]{2}{*}{ Groups studied } & \multirow[b]{2}{*}{$\begin{array}{l}\text { Apolipoprot-in in } \mathrm{A} 1 \\
(\mathrm{mg} / \mathrm{dL}) \text { mean } \pm \mathrm{SD}\end{array}$} & \multicolumn{3}{|c|}{$P$ value } \\
\hline & & Diabetic children & $\begin{array}{c}\text { Healthy children with } \\
\text { diabetic parent }\end{array}$ & $\begin{array}{c}\text { Healthy children with } \\
\text { nondiabetic parent }\end{array}$ \\
\hline Diabetic children & $153 \pm 69$ & - & 0.27 & 0.62 \\
\hline Healthy children with diabetic parent & $128 \pm 56$ & 0.27 & - & 0.80 \\
\hline Healthy children with nondiabetic parent & $138 \pm 58$ & 0.62 & 0.80 & - \\
\hline
\end{tabular}

TABLe 2: Comparison of apoB levels in diabetic children, healthy children with diabetic parent(s), and healthy children with nondiabetic parent(s).

\begin{tabular}{lcccc}
\hline Groups studied & $\begin{array}{c}\text { Apolipoprot-in B } \\
(\mathrm{mg} / \mathrm{dL}) \text { mean } \pm \text { SD }\end{array}$ & $\begin{array}{c}P \text { value } \\
\text { Diabetic children }\end{array}$ & $\begin{array}{c}\text { Healthy children with } \\
\text { diabetic parent }\end{array}$ & $\begin{array}{c}\text { Healthy children with } \\
\text { nondiabetic parent }\end{array}$ \\
\hline Diabetic children & $127 \pm 47$ & - & 1.00 & 0.001 \\
Healthy children with diabetic parent & $128 \pm 38$ & 1.00 & - & $<0.0001$ \\
Healthy children with nondiabetic parent & $90 \pm 21$ & 0.001 & $<0.0001$ & - \\
\hline
\end{tabular}

with decreased athero-protective apoA levels [3]. Fasting and postprandial apoB in diabetic patients is higher than healthy persons [6]. Improvement in control of type II DM was associated with decreased level of postprandial chylomicrons and lower transport of cholesterol to the apoB lipoproteins [7]. Plasma apoA1 and apoB levels are stronger predictors of premature atherosclerosis than other plasma lipoproteins [8]. Apoproteins are important risk factors for coronary artery disease in future for children with greater risk of atherosclerosis [9]. In one study on diabetic children, increased plasma apoB and dense LDL were associated with poor diabetic control [10].

In our study, in diabetic children apoB levels were higher than healthy children with and without diabetic parent(s). Plasma levels of apoA in diabetic patients were nonsignificantly higher than healthy children. In children with diabetic parent(s) plasma levels of apoA was nonsignificantly lower than healthy children with nondiabetic parent(s). In these children, plasma levels of apoB were nonsignificantly higher than healthy children with nondiabetic parent(s). Then, healthy children with diabetic parent(s) are at greater risk of atherosclerosis and screening for plasma apoA and apoB levels may be helpful in these children. Given the role of healthy lifestyle in prevention and control of non-communicable diseases [11], the barriers to healthy habits should be determined [12], and families should be encouraged for screening and preventive programs.

\section{Conclusions}

For primordial and primary prevention of atherosclerotic diseases, we suggest screening diabetic children and healthy children with diabetic parents for low plasma apoA1 and high plasma apoB.

\section{Conflict of Interests}

Authors declare that they have no conflict of interests.

\section{References}

[1] S. D. Colan and J. W. Newburger, "Acquired heart diseae in children," in Textbook of Heart Disease, E. Braunwald, D. Zipes, and P. Libby, Eds., pp. 1637-1638, WB Sunders Company, Philadephia, Pa, USA, 2001.

[2] A. Chait and S. Haffner, "Diabetes, lipids and atherosclerosis," in Textbook of Endocrinology, L. J. DeGroot and J. L. Jameson, Eds., vol. 1, p. 941, WB Sunders Company, Philadelphia, Pa, USA, 2001.

[3] A. Chait and S. Haffner, "Diabetes, lipids and atherosclerosis," in Textbook of Endocrinology, L. J. DeGroot and J. L. Jameson, Eds., vol. 1, p. 942, WB Sunders Company, Philadelphia, Pa, USA, 2001.

[4] A. Chait and S. Haffner, "Diabetes, lipids and atherosclerosis," in Textbook of Endocrinology, L. J. DeGroot and J. L. Jameson, Eds., vol. 1, pp. 946-947, WB Sunders Company, Philadelphia, Pa, USA, 2001.

[5] O. Ziegler, L. Méjean, B. Igau, J. C. Fruchart, P. Drouin, and C. Fiévet, "Accessibility of human apolipoprotein B-100 epitopes in insulin-dependent diabetes: relation with the surface lipid environment of atherogenic particles," Diabetes and Metabolism, vol. 22, no. 3, pp. 179-184, 1996.

[6] R. Mangat, J. W. Su, J. E. Lambert et al., "Increased risk of cardiovascular disease in Type 1 diabetes: arterial exposure to remnant lipoproteins leads to enhanced deposition of cholesterol and binding to glycated extracellular matrix proteoglycans," Diabetic Medicine, vol. 28, no. 1, pp. 61-72, 2011.

[7] F. Pont, L. Duvillard, E. Florentin, P. Gambert, and B. Vergès, "High-density lipoprotein apolipoprotein A-I kinetics in obese insulin resistant patients. An in vivo stable isotope study," International Journal of Obesity, vol. 26, no. 9, pp. 1151-1158, 2002.

[8] Z. Li, Y. Xu, S. Tan, B. Song, and M. Liu, "Study of plasma levels of apoa-i and apob for prognosis of acute ischemic stroke," Life Science Journal, vol. 6, no. 2, pp. 51-56, 2009.

[9] K. Aasvee, E. Kurvinen, J. Sundvall, M. Jauhiainen, and I. Tur, "Aggregation of lipoprotein and inflammatory parameters in families with a history of premature myocardial infarction: the Tallinn Myocardial infarction study," Clinical Chemistry and Laboratory Medicine, vol. 46, no. 11, pp. 1602-1608, 2008. 
[10] J. J. Albers, S. M. Marcovina, G. Imperatore et al., "Prevalence and determinants of elevated apolipoprotein B and dense lowdensity lipoprotein in youths with type 1 and type 2 diabetes," Journal of Clinical Endocrinology \& Metabolism, vol. 93, no. 3, pp. 735-742, 2008.

[11] L. Stoner, K. R. Stoner, J. M. Young, and S. Fryer, "Preventing a cardiovascular disease epidemic among indigenous populations through lifestyle changes," International Journal of Preventive Medicine, vol. 3, no. 4, pp. 230-240, 2012.

[12] R. Kelishadi, S. Ghatrehsamani, M. Hosseini, P. Mirmoghtadaee, S. Mansouri, and P. Poursafa, "Barriers to physical activity in a population-based sample of children and adolescents in Isfahan, Iran," International Journal of Preventive Medicine, vol. 1, no. 2, pp. 131-137, 2010. 


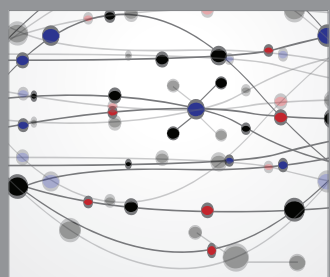

The Scientific World Journal
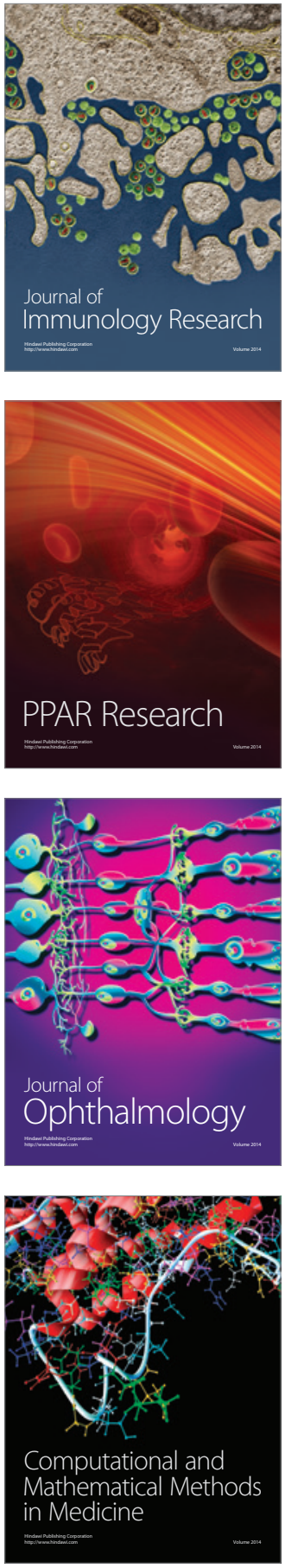

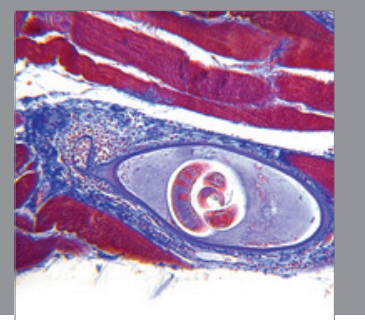

Gastroenterology

Research and Practice
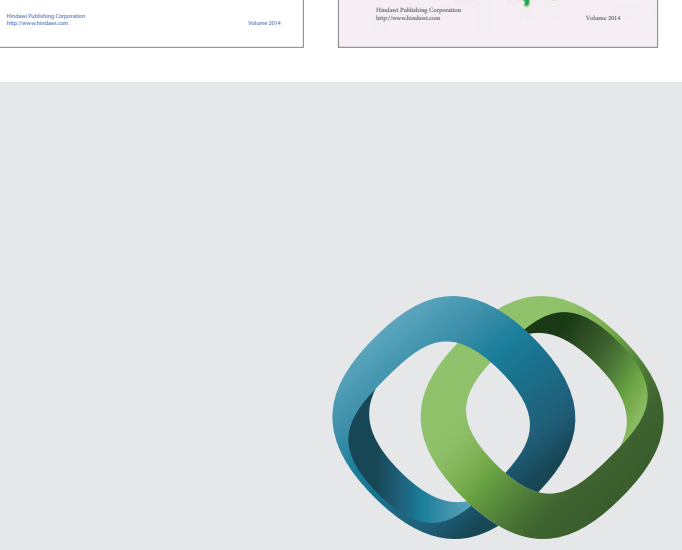

\section{Hindawi}

Submit your manuscripts at

http://www.hindawi.com
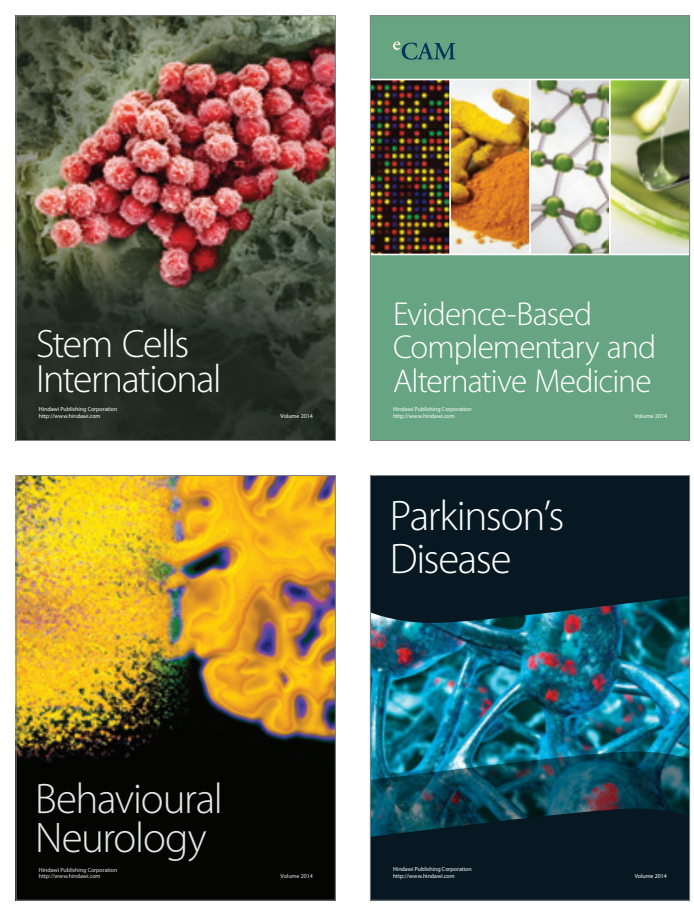

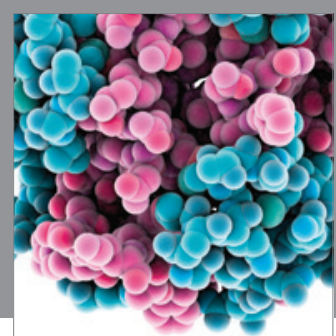

Journal of
Diabetes Research

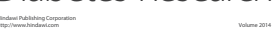

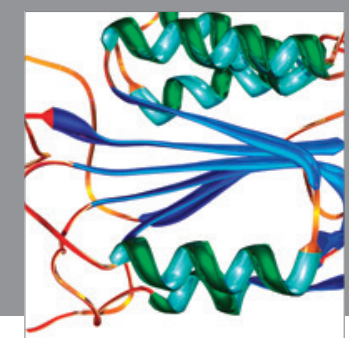

Disease Markers
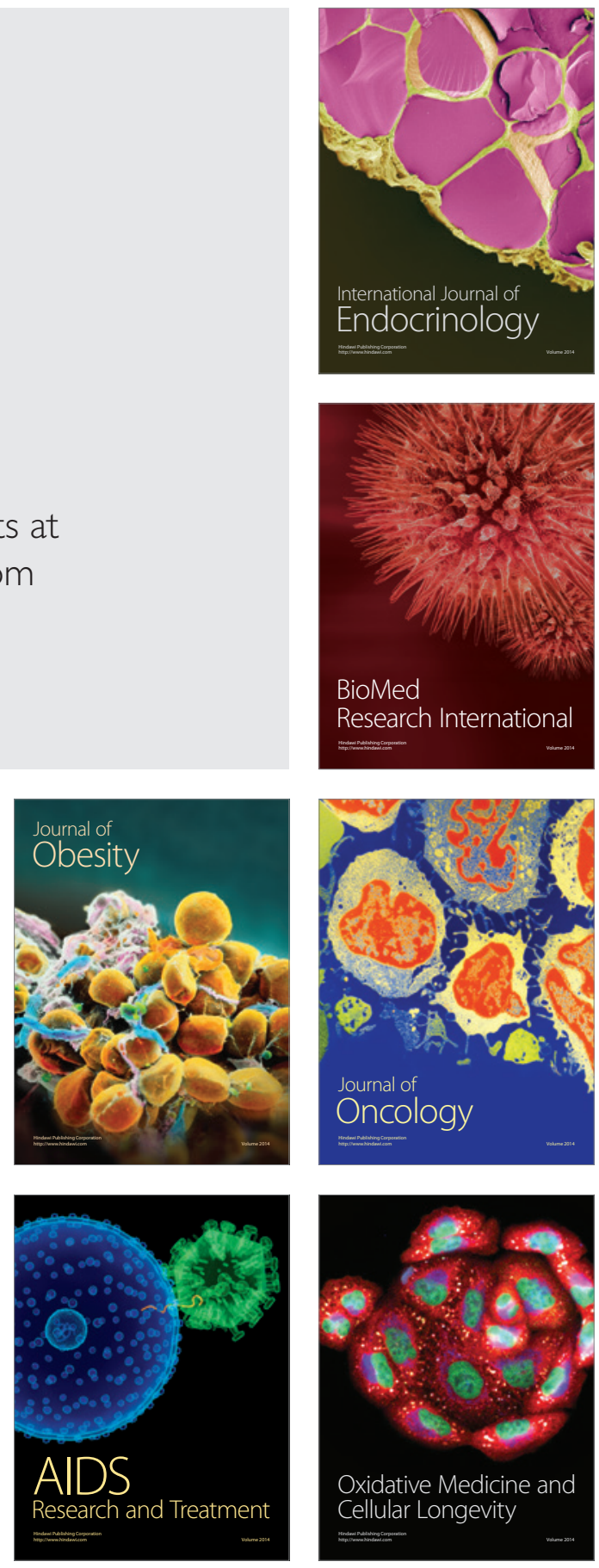